\title{
$\mathrm{CNN}$ 을 이용한 레이다 신호 자동 분류
}

\section{Automatic Classification of Radar Signals Using CNN}

\author{
홍석준 · 이연규· 조제일* · 이상길** · 서보석 \\ Seok-Jun Hong $\cdot$ Yearn-Gui Yi $\cdot$ Jeil Jo* · Sang-Gil Lee** $\cdot$ Bo-Seok Seo \\ 요 약
}

이 논문에서는 수신된 레이다 신호의 특징 파라미터 데이터에 기계학습 방법을 적용하여 위협 형태에 따라 레이다 신호를 분류하는 방법을 제시한다. 현재 군에서는 위협 신호를 파악하기 위해 특징 파라미터값들과 위협 형태의 대응관 계를 나타내는 라이브러리를 이용한다. 라이브러리를 이용한 방법은 새로운 위협이나 기존 라이브러리에 존재하지 않는 위협 형태에 대해서 레이다 신호를 분류하기 어렵고 위협 형태를 파악하는데 문제가 있다. 이 논문에서는 라이브러리 없이 특징 파라미터 데이터만을 이용하여 위협 형태에 따라 레이다 신호를 분류하는 방법을 제안하고자 한다. 분류기로 는 $\mathrm{CNN}$ (convolutional neural network)을 사용하며, 기계학습을 적용하여 훈련시킨다. 제안 방법은 라이브러리를 사용하지 않음으로써 새로운 위협 신호나 기존의 라이브러리에 존재하지 않는 위협 신호도 적응적으로 분류할 수 있다.

\begin{abstract}
In this paper, we propose a classification method for radar signals depending on the type of threat by applying machine learning to parameter data of radar signals . Currently, the army uses a library of mapping relations between the parameters and the types of threat to recognize threat signals. This approach has certain limitations when classifying signals and recognizing new types of threat or types of threat that do not exist in the current libraries. In this paper, we propose an automatic radar signal classification method depending on the type of threat that uses only parameter data without a library. A convolutional neural network is used as the classifier and machine learning is applied to train the classifier. The proposed method does not use a library, and hence, can classify threat signals that are new or do not exist in the current library.
\end{abstract}

Key words: Radar Signal Classification, Jamming Technique, Machine Learning, Convolution Neural Network

\section{I. 서 론}

레이다는 목표물을 향해 전파를 발사한 후 되돌아오는 반사파를 분석하여 그 목표물의 거리, 방향, 형상, 속도 등을 파악하는 전자장치를 말한다. 가장 일반적인 펄스
레이다의 경우, 그림 1 과 같이 반송파로 변조된 짧은 펄 스를 연속적으로 방사하여 목표물을 탐색하고, 추적 및 감시하는 기능을 수행한다 ${ }^{[1]}$. 이러한 레이다 신호는 주파 수(radio frequency: RF), 펄스폭, 펄스 반복 간격(pulse repetition interval: PRI), 펄스 진폭, 피크전력, 편파와 기타 변

\footnotetext{
충북대학교 전자공학과(Department of Electronics Engineering, Chungbuk National University)

*국방과학연구소(Agency for Defense Development)

**동아방송예술대학교 방송예술융합학부(Dong-Ah Institute of Media and Arts)

- Manuscript received October 17, 2018 ; Revised December 11, 2018 ; Accepted January 31, 2019. (ID No. 20181017-109)

- Corresponding Author: Bo-Seok Seo (e-mail: boseok@cbnu.ac.kr)
} 
조방식 등의 특징변수로 특징지을 수 있다 ${ }^{[1],[2]}$.

레이다 재밍(jamming)은 상대 레이다의 방사파에 대해 방해전파를 방사하여 반사되어 되돌아가는 레이다 신호 를 의도적으로 교란시키는 것을 말한다. 이러한 재밍의 최종 목적은 적 레이다의 기능을 무력화시키는 것으로 현대의 전자전에서는 매우 중요한 역할을 한다 ${ }^{[1],[2]}$.

한편, 레이다 재밍은 레이다 신호의 형태에 따라 즉 위 협체계에 따라 다른 방법을 적용해야 하며, 효과적인 방 법은 이미 잘 알려져 있다 ${ }^{[1,[3]}$. 현재 주로 적용하고 있는 재밍기법 선택방법은 기 구축된 위협 라이브러리를 기반 으로 각 위협에 대해 재밍기법을 할당하는 방식이다 ${ }^{[3]}$. 위협 라이브러리는 장기간에 걸쳐 레이다의 신호를 수집 하고 분석하여 신호의 특징변수에 따라 특정 레이다 신 호에 최적의 재밍기법을 적용하도록 구축된다 ${ }^{[3]}$. 그러나 레이다와 레이다 재밍의 관계는 끊임없이 반복적으로 순 환하는 창과 방패의 싸움과도 같아서, 재밍 기술의 발전 에 따라 적 레이다의 형태도 지속적으로 변화되고 개선 되고 있다. 그 결과로 새로운 위협이나 기존의 라이브러 리에 존재하지 않는 위협에 대해서는 적절한 재밍기법을 할당하는데 제한이 따른다.

따라서 적의 위협에 대비한 방해기술을 확보하기 위해 서는 라이브러리 기반이 아닌 새로운 재밍기법 선택방법 을 강구할 필요가 있다. 기계학습은 이러한 목적에 잘 부 합되는 방법 중의 하나이다.

기계학습은 학습이라는 경험을 통해서 유사하거나 동 일한 문제를 더 효율적으로 처리할 수 있도록 시스템의 구조나 파라미터를 바꾸는 것을 말한다. 즉 이미 알고 있 는 것으로부터 모르는 것을 추론하기 위한 알고리듬을 설계하는 것으로 볼 수 있다 $[4],[5]$.

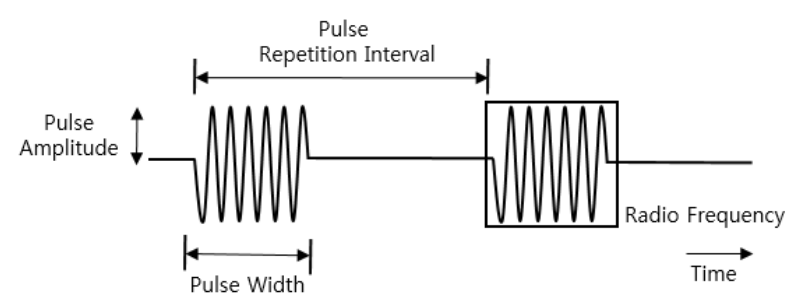

그림 1. 일반적인 펄스 레이다 신호

Fig. 1. Typical pulse radar signals.
현재 컴퓨터의 학습 능력을 키울 수 있는 다양한 기계 학습 알고리듬이 존재한다. 이 중에서 영상 데이터에 대 하여 광범위하게 응용되고 있는 콘볼루션 신경망(convolutional neural network: $\mathrm{CNN}$ )은 입력이 특정 패턴 또는 패 턴의 변환을 포함하는 경우 우수한 성능을 나타낸다[5],[6].

한편, 레이다는 탐색, 추적, 감시 등의 기능에 따라 신 호의 특징변수가 특정한 패턴을 가지고 변화한다. 따라서 이러한 변화 패턴을 2 차원 영상으로 나타내면 $\mathrm{CNN}$ 을 적 용하여 레이다 신호를 분류할 수 있다.

저자는 참고문헌 [7]에서 특징변수 RF와 PRI를 영상화 하고 $\mathrm{CNN}$ 을 적용하여 대응하는 재밍기법에 따라 레이다 신호를 분류하는 방법을 제시하였다. 제안 방법은 학습 데이터에 포함되어 있지 않은 전혀 새로운 레이다 신호 에 대해서도 $90 \%$ 이상의 분류확률을 나타내었다. 그러 나 특징변수가 특정한 변화 패턴이 없는 경우, 즉 일정한 값을 유지하는 경우 오분류가 자주 발생하였다.

이 논문에서는 참고문헌 [7]의 문제점을 개선한 $\mathrm{CNN}$ 기반의 레이다 신호 분류방법을 제시하고자 한다. 특징변 수의 절대값을 영상에 반영하기 위해 전체 신호에 대한 특징변수의 최소값 및 최대값을 이용한다. 제안한 분류기 는 기존의 라이브러리를 바탕으로 생성한 특징변수 데이 터를 학습 데이터로 사용한다.

이 논문의 구성은 다음과 같다. II 장에서는 라이브러 리를 이용한 기존의 레이다 신호 분류 방법에 대해 설명 하고, III장에서는 제안한 $\mathrm{CNN}$ 기반 분류기의 구조 및 분 류 방법에 대해 설명한다. $\mathrm{N}$ 장에서는 모의실험 결과를 제시하고, $\mathrm{V}$ 장에서 결론을 맺는다.

\section{II. 라이브러리를 이용한 기존의 레이다 신호 분류 방법}

이 논문에서 분류하고자 하는 레이다 신호는 현대전에서 주로 사용하는 펄스 레이다의 수신 신호라고 가정한다.

라이브러리를 이용하여 재밍기법을 선택하는 기존의 방법, 즉 위협의 형태를 파악하는 방법은 크게 그림 2와 같이 수신한 레이다 신호로부터 특징변수를 추출하는 단 계, 특징변수를 분석하여 각 변수의 변화 형태를 파악하 는 단계, 그리고 이로부터 적용할 재밍 방법을 선택하는 단계의 3 단계로 구성된다. 


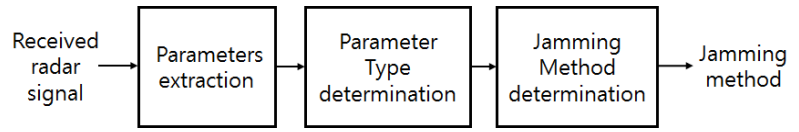

그림 2. 기존의 라이브러리를 이용하는 레이다 신호 분 류방법

Fig. 2. Structure of the conventional library based radar signal classification method.

주로 이용하는 펄스 레이다 신호의 특징변수로는 RF, 펄스폭, PRI, 펄스 진폭, 펄스 변조방식 등이 있다 ${ }^{[3]}$. 각각 의 특징변수는 시간에 따라 반복적인 또는 불규칙적인 패턴을 가지고 변화한다.

그림 3은 PRI의 대표적인 8개 변화 형태를 나타낸다. 고정적(stable)인 경우는 시간에 따라 PRI 값이 변함없이 일정한 경우이고, 지터(jitter) 형태는 매 펄스마다 불규칙 적으로 변하는 경우, 스태거(stagger)는 정해진 고정값을 규칙적으로 반복하는 경우, 체류변경(dwell \& switch)은 몇 개의 주어진 값에 대해 일정 시간동안 유지했다가 불 규칙적으로 변하는 경우로 도약(hopping) 형태라고도 한 다. 그 외에 정현파, +톱니파, - 톱니파, 삼각파 등의 형태
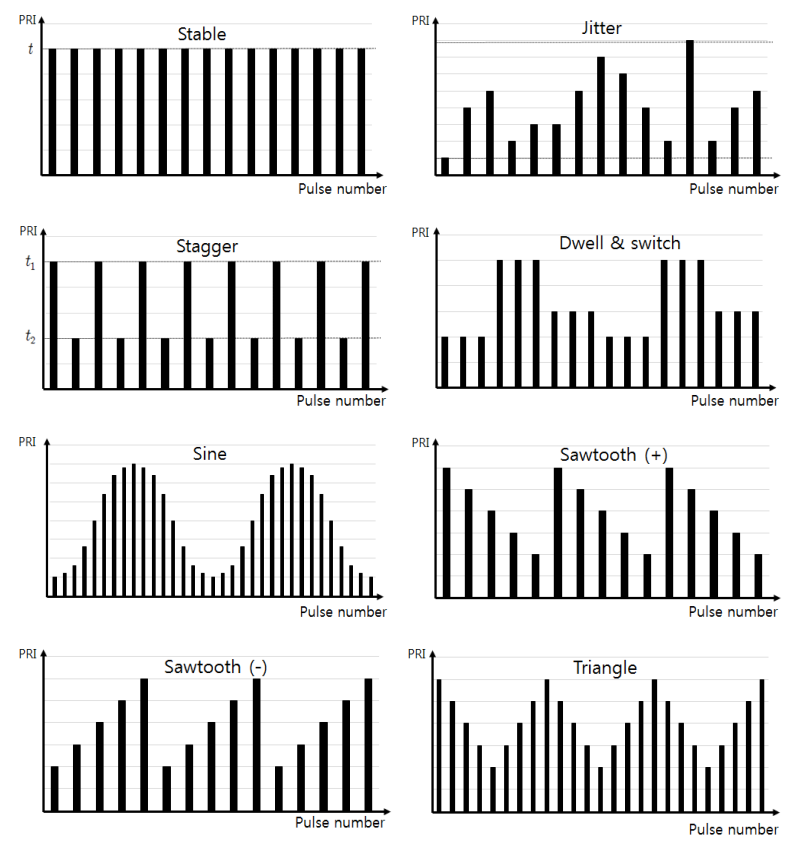

그림 3. PRI의 대표적인 변화 형태

Fig. 3. Typical variation types of PRI.
가 있다. 실제 환경에서는 이 외에도 다른 여러 형태가 존 재한다.

기존의 라이브러리 이용방법에서는 마지막으로 특징 변수의 변화 형태를 파악하고, 라이브러리를 검색하여 어 떤 레이다인가를 추정한 후, 이에 대응하기 위한 재밍기 법을 선택한다. 이와 같이 위협 라이브러리를 이용한 재 밍기법 선택 방법은 라이브러리에 존재하지 않는 레이다 신호나 새로운 위협 신호에 대해서는 적절한 재밍기법을 할당하기 어려운 문제가 있다.

\section{CNN을 이용한 레이다 신호 분류}

제안한 레이다 신호 분류기는 그림 4와 같은 구조를 가 진다. 이 논문에서는 레이다 신호를 분류하기 위해서 수 신 신호로부터 추출된 특징변수 데이터를 이용하며, 특징 변수는 특정의 레이다에 대한 수신신호로부터 추출되었 다고 가정한다. 또한 여러 가지 특징변수 중에서 가장 중 요한 RF와 PRI만을 고려한다.

두 종류의 특징변수 데이터는 먼저 정규화를 거치고 2 차원 영상으로 변환된 다음 $\mathrm{CNN}$ 에 입력된다. $\mathrm{CNN}$ 의 각 출력 노드는 재밍 방법에 해당하는 위협 형태의 그룹이 되며, 출력값은 입력신호에 해당하는 레이다가 그 그룹에 속할 확률에 해당된다. 따라서 제안 방법에서는 레이다 신호의 특징변수를 몇 가지의 전처리를 거친 후, 그대로 $\mathrm{CNN}$ 에 입력하면 곧바로 재밍 방법에 해당하는 그룹이 출력된다. 즉, 기존의 라이브러리를 이용하는 방법과 다르 게 특징변수의 변화 형태를 파악하는 중간 단계가 없다.

\section{3-1 학습 및 검증 데이터 생성}

$\mathrm{CNN}$ 을 학습시키기 위한 학습 데이터 입출력쌍은 특정 레이다 신호의 RF 및 PRI 데이터와 해당 레이다에 대응

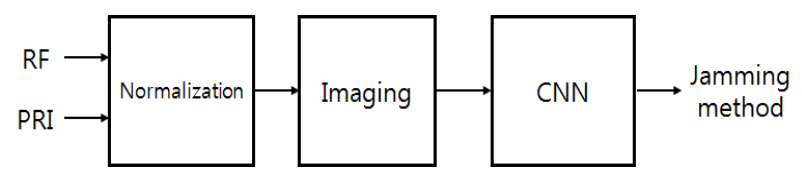

그림 4. 제안한 $\mathrm{CNN}$ 기반의 레이다 신호 분류 방법

Fig. 4. Structure of the proposed CNN based radar signal classification method. 
하기 위한 재밍 기법이 된다. 레이다의 특징변수 RF와 PRI 데이터는 레이다 모의기에서 생성된 펄스레이다 신호로 부터 취득한 신호의 특성 데이터를 바탕으로 생성된다. $\mathrm{PRI}$ 는 II 장에서 예를 든 8 가지 형태로 발생시키며, RF는 고정(stable), 고속변화(agile), 도약(hopping), 정현파, -톱 니파, +톱니파, 삼각파 등 7 가지의 변화 형태를 고려한다. 생성된 데이터는 $\mathrm{CNN}$ 의 학습뿐만 아니라, 성능 검증에 도 사용되는데, 이 때 학습에 사용된 데이터는 제외된다.

\section{3-2 특징변수의 전처리 및 영상화}

$\mathrm{CNN}$ 을 학습하기 위해서 레이다의 특성 데이터인 $\mathrm{RF}$ 와 PRI를 반영하여 2차원으로 영상화한다. 또 영상화 전 에 데이터의 범위를 제한하기 위해 정규화를 적용한다.

레이다 신호의 특징변수인 RF와 PRI 데이터 값은 매우 넓은 범위에서 변화한다. 특히 PRI 값의 변화 범위는 크 게는 수 천배에 달한다. 따라서 넓은 동적범위에 걸친 $\mathrm{RF}$ 와 PRI 값의 변화 형태를 인식하기 위해서는 각 데이터의 최소값과 최대값을 기준으로 데이터 값을 일정 범위 이 내로 정규화할 필요가 있다. 이 논문에서는 0 과 1 사이로 정규화한다.

정규화된 RF와 PRI 데이터를 영상화하는 방법은 여러 가지를 생각할 수 있다. 그림 5는 단순히 RF와 PRI를 번 갈아 가며 순차주사(progressive scan) 방식으로 변환한 영 상을 나타낸다. 이 경우, RF와 PRI 각각 $2 \times 1,000$ 인 1 차원 행렬을 40×50 회색조(gray) 영상으로 변환한다. 만일 영상 을 완성하기 위한 데이터의 수가 부족하면 부족한 개수 만큼 앞부분을 복사하여 순환적으로 채워 넣는다. 이것

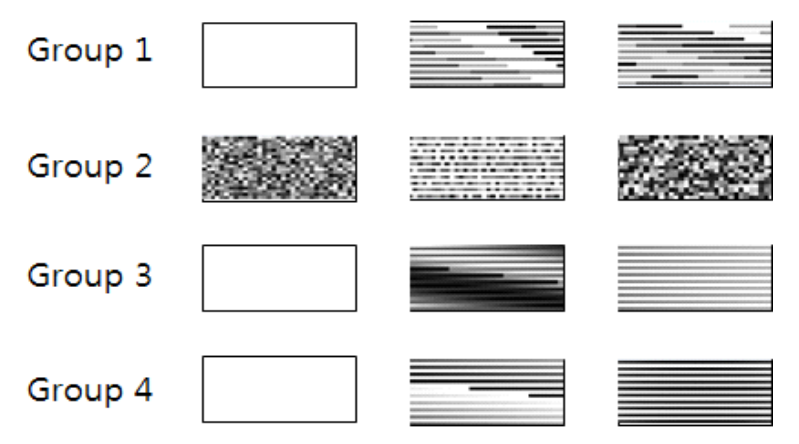

그림 5. RF 및 PRI 데이터의 영상화 결과

Fig. 5. Results of imaging of RF and PRI data.
은 레이다의 RF 또는 PRI 값의 변화가 주기적으로 반복 되기 때문이다.

그림 5 에서 그룹 $\mathrm{n}$ 은 $\mathrm{n}$ 번 재밍 기법을 적용하는 레이다 신호들의 집합을 의미한다. RF와 PRI 값은 0 과 1 사이로 정규화시켰기 때문에, 최대값인 1 은 흰색으로 최소값인 0 은 검정색인 영상이 형성된다. 그림을 보면 첫 번째 열을 제외하고, 그룹에 따라 영상패턴의 모양이 조금씩 다르게 나타나는 것을 알 수 있다.

단순히 RF와 PRI 값을 정규화하여 회색조 영상으로 나 타내면 절대값이 반영되지 않아 영상에서 구별이 안 되는 문제가 있다 ${ }^{[7]}$. 그림 6 은 각 그룹에 속하는 특정 레이다 신호의 PRI의 변화 범위를 예로 들어 나타낸 것이다. 그 림에서 그룹 1 과 3 의 경우와 같이 PRI 변화 형태가 고정 적(stable)이면서 어떤 범위를 가지는 것은 그 구간 내에 서 불규칙적인 특정값으로 고정되는 것을 의미한다. 이 경우 특정 고정값을 가지면 절대값이 얼마이든 그 값이 동일하게 1 로 정규화되어 구별할 수 없게 된다. 그림 5 첫 번째 열의 Group $1,3,4$ 가 이에 해당한다. 또, 그룹 2와 4 의 경우와 같이 PRI 절대 크기는 다르지만 패턴이 동일 한 경우에도 정규화된 값을 구별할 수 없게 된다. 그림 7 은 그림 6에서 예를 든 4개 그룹의 PRI 데이터를 영상화 한 결과를 나타낸다.

이 문제는 데이터의 최소값과 최대값 정보를 영상에 반영함으로써 해결할 수 있다. PRI의 최소값을 반영하는 방법은 다음과 같다. 4 개 그룹에 속하는 전체 레이다 신 호에 대한 PRI 최소값 중에서 가장 작은 값과 가장 큰 값 을 적절한 개수의 등간격 구간으로 나눈 벡터를 설정한

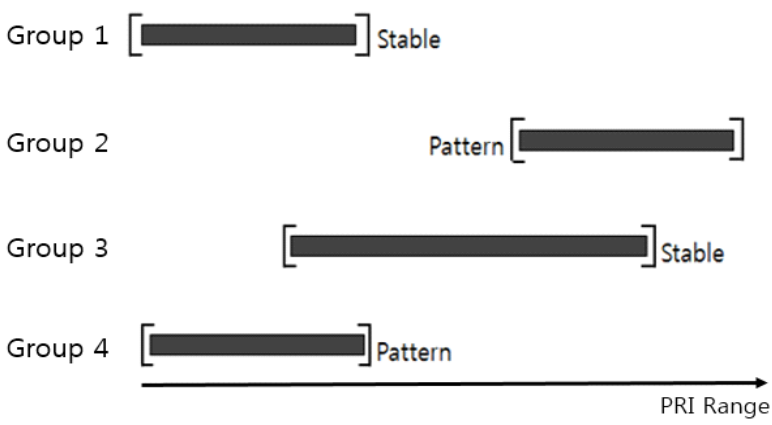

그림 6. 특성변수 PRI 값의 변화 범위

Fig. 6. Variation range of PRI. 


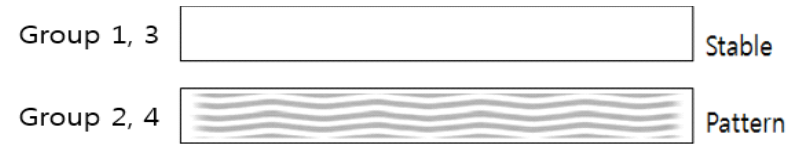

그림 7. 그림 6과 같은 변화 범위를 가지는 PRI 데이터의 영상화 결과

Fig. 7. Images for PRI data with the range of Fig. 6.

다 (이 벡터를 최소값 구간벡터라 부르기로 한다). 영상화 하고자 하는 PRI 데이터가 주어지면 최소값 구간벡터를 그 데이터의 최소값으로 나누어준다.

그림 8 은 최소값 중에서 가장 작은 값이 1 , 가장 큰 값 이 100 인 경우, 구간 간격을 1 로 놓고 원소의 개수가 100 개인 최소값 구간벡터를 생성했을 때, 고정값이 각각 25 , 75 인 PRI 데이터를 변환하여 형성된 한 줄의 영상을 나타 낸다. 앞의 단순영상 형성 방법을 적용하면 두 경우 모두 값이 1이 되고, 변화가 없는 동일한 밝기로 나타난다. 그 러나 최소값 구간벡터를 정의함으로써 절대값이 두 경우 서로 다른 영상이 형성됨을 볼 수 있다.

$\mathrm{PRI}$ 의 최대값과, $\mathrm{RF}$ 의 최소값 및 최대값에 대해 동일 한 방법을 적용하여 구간벡터를 정의함으로써 영상 데이 터에 RF와 $\mathrm{PRI}$ 의 최대값과 최소값을 반영할 수 있다.

새로운 영상은 모든 변화 형태의 데이터에 대해 본래 의 RF와 PRI 데이터, 추가된 RF와 PRI의 최소값 및 최대 값 반영 데이터 등 모두 6종류의 데이터로 구성된다. 이 때 데이터의 종류가 2 개에서 6 개로 늘어나서 계산량이 증가하게 되지만, 첫 계층에만 영향을 미치므로 전체적으 로 계산량의 증가는 미미하다.

그림 9는 그림 5의 첫 번째 열에서 구별이 안 되는 영 상에 대해 4개의 구간벡터를 정의하고, 이를 이용하여 얻 은 영상을 나타낸다. 고정된 상수의 RF 또는 PRI 데이터가

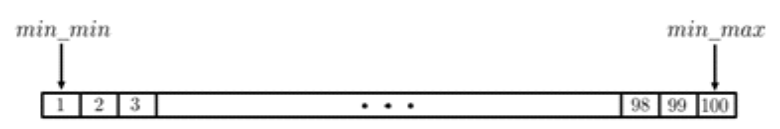

$\min (25)$

$\min (75)$

그림 8. 데이터의 동적범위 정보를 반영한 영상화 결과 Fig. 8. Images reflecting the dynamic range of PRI data.

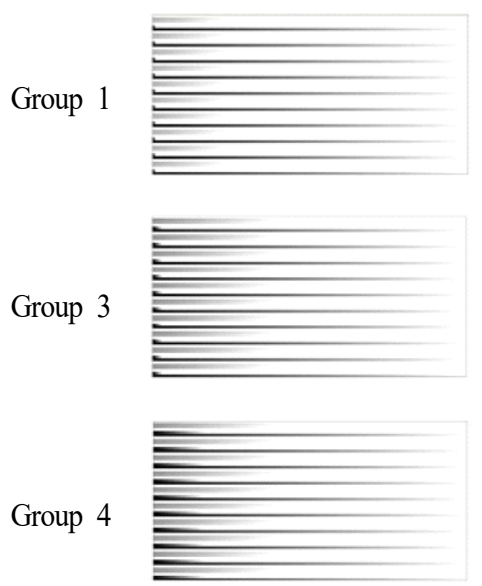

그림 9. RF와 $\mathrm{PRI}$ 의 동적 범위 정보를 반영한 영상화 결과 Fig. 9. Images reflecting the dynamic ranges of RF and PRI data.

있는 경우, 정규화한 부분은 동일한 흰색으로 나타나지 만, 최소값 및 최대값을 반영한 회색 및 검은색 부분이 서 로 다른 밝기의 영상으로 나타나는 것을 확인할 수 있다.

\section{3-3 CNN 학습}

최근 $\mathrm{CNN}$ 을 이용한 영상 특징 추출은 컴퓨터 영상 분 야에서 다양하게 적용되고 있다 ${ }^{[5],[8]} . \mathrm{CNN}$ 은 콘볼루션 계 층과 풀링 계층을 번갈아가며 수행함으로써 학습 데이터 의 특징을 추출한다 ${ }^{[5],[9] .}$

제안한 $\mathrm{CNN}$ 구조는 그림 10 과 같이 3 개의 콘볼루션층 (convolution layer)과 풀링층(pooling layer), 그리고 완전연 결된 2개 은닉층을 가진 신경망으로 구성된다. 특징변수 데이터로 형성된 입력 영상은 작은 블록 단위로 동시에 입력되어 콘볼루션 계층의 한 점에 대응된다. 이와 같이 대응시킴으로써 입력 영상은 더 작은 크기의 영상으로 이루어진 콘볼루션층을 구성하게 된다. 은닉층은 다시 작 은 조각으로 나뉘어 각 조각마다 특징값이 대응되는 부 분표본화(subsampling) 과정을 거친다. 콘볼루션층과 부분 표본화층은 짝을 이루어 구성되며, 보통 $\mathrm{CNN}$ 은 이러한 짝이 여러 개 모여 은닉층을 구성하게 된다. 제안 방식에 서는 마지막 3 번째 풀링층에서는 콘볼루션 다음에 부분 표본화를 거치지 않고 그대로 완전연결된 신경망에 입력 된다. 


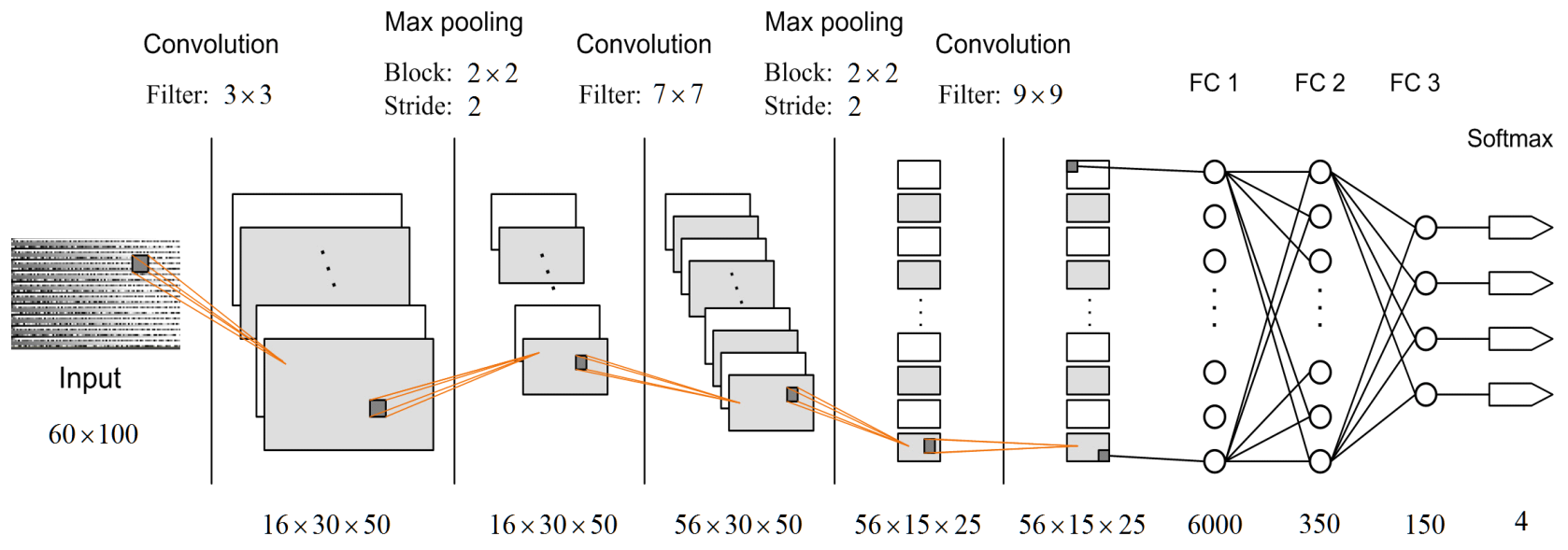

그림 10. $\mathrm{CNN}$ 구조

Fig. 10. Structure of the CNN.

$\mathrm{CNN}$ 구조를 정확하게 결정하기 위해서는 하이퍼파라 미터를 설정해야 한다. 하이퍼파라미터는 콘볼루션 연산 에 필요한 필터의 길이 및 필터의 개수, 풀링에 필요한 윈 도우 크기(pool size) 및 풀링 폭(stride), 그리고 은닉층 출 력의 개수 등으로 구성된다.

하이퍼 파라미터는 $\mathrm{CNN}$ 의 비선형성 때문에 해석적 방 법으로 결정하기는 매우 어렵다. 제안 방식에서는 풀링층 의 윈도우 크기와 폭은 고정시킨 후, 콘볼루션 층의 필터 크기, 필터개수, 은닉층의 출력 개수를 바꾸어 가며 모의 실험에 의해 경험적으로 최적의 파라미터를 구하였다.

먼저 모든 콘볼루션층의 필터 개수를 제외한 나머지 파라미터들은 고정시킨 후, 필터 개수를 바꾸어가며 모의 실험을 한다. 결과 중에서 가장 좋은 성능을 보인 필터개 수를 고정시킨다. 그 다음 필터개수와, 은닉층의 출력 개 수도 같은 방법으로 모의실험을 하여 결정한다.
최종적으로 결정된 하이퍼파라미터는 표 1 에 나타낸 바와 같다. 표에서 [n1:n2:n3]는 $\mathrm{n} 1$ 부터 $\mathrm{n} 2$ 간격으로 $\mathrm{n} 3$ 까 지 변화시키는 것을 의미한다.

\section{N. 모의실험 결과}

모의실험은 먼저 $\mathrm{CNN}$ 을 학습시킨 후 분류성능을 평 가하는 과정으로 구분된다. RF와 PRI 값만 이용하여 단 순하게 영상을 형성한 경우와 최대값, 최소값을 반영하 여 영상을 형성한 경우에 대한 성능을 비교한다. 레이다 모의기로부터 얻은 7,000개 레이다의 특징변수 특성을 기반으로, 각 레이다에 대해 $\mathrm{RF}$ 와 PRI 데이터를 각각 1,000 개씩 불규칙적으로 발생시킨다. 특징변수 값의 변 화 형태에 따라 세부적으로 데이터룰 생성하는 방법은 다음과 같다.

표 1. $\mathrm{CNN}$ 의 하이퍼 파라미터 설정

Table 1. Setting of hyperparameters of the CNN.

\begin{tabular}{|c|c|c|c|c|c|c|c|}
\hline \multicolumn{2}{|c|}{$1^{\text {st }}$ convolution layer } & \multicolumn{2}{c|}{$2^{\text {nd }}$ convolution layer } & \multicolumn{2}{c|}{$3^{\text {rd }}$ convolution layer } & \multicolumn{2}{c|}{ Fully connected layer } \\
\hline Filter size & Filter number & Filter size & Filter number & Filter size & Filter number & 1st layer & 2nd layer \\
\hline$[3: 2: 9]$ & 16 & {$[3: 2: 9]$} & 32 & {$[3: 2: 9]$} & 64 & 100 & 50 \\
\hline 3 & {$[8: 8: 64]$} & 7 & {$[8: 8: 64]$} & 9 & {$[8: 8: 64]$} & 100 & 50 \\
\hline 3 & 16 & 7 & 56 & 9 & 56 & {$[50: 50: 400]$} & {$[50: 50: 400]$} \\
\hline 3 & 16 & 7 & 56 & 9 & 56 & 350 & 150 \\
\hline
\end{tabular}


(1) Stable(fixed) : 주어진 전체 구간 내에서 무작위로 값 을 선택하여 데이터 개수만큼 생성함.

(2) Jitter(agile) : 세부구간 내에서 균일분포를 가지도록 무작위로 생성함 (세부구간은 주어진 전체 구간 $1 / 10$ 의 배수로 최소, 최대값을 무작위로 선택하여 결정하며, stable을 제외하고 모두 세부구간 내에서 데이터를 발생시킴).

(3) Stagger : 2 32 사이에서 무작위로 계단 개수를 설 정하고, 각 계단의 값이 세부구간 내에서 균일분포 를 가지도록 매 데이터마다 무작위로 생성함.

(4) Dwell \&switch(hopping): Stagger 방법과 동일하게 계 단 개수 및 값을 결정하며, 정해진 데이터 수 1,000 개 내에서 변화 주기가 3 7개 포함되도록 무작위 로 주기를 설정함.

(5) Sine : 3 7 사이에서 무작위로 선택된 주기에 대해, 주어진 세부구간 사이를 진동하는 정현파값을 발생 함. 세부구간은 전체 구간의 $1 / 10$ 이상이 되도록 무 작위로 선택함.

(6) Sawtooth+/Sawtooth-: 3 7 사이에서 무작위로 선 택된 주기에 대해, 선택된 세부구간 사이를 왕복하 는 $+/$ - 톱니파 값을 발생함.

(7) Triangle : 3 7 사이에서 무작위로 선택된 주기에 대해, 선택된 세부구간 사이를 왕복하는 삼각파 값 을 발생.

사용하는 세부구간 크기, 계단의 개수, 한 번 처리하는 데이터의 개수 및 포함되는 주기 개수 등은 레이다 신호 분류 시 실제 적용하는 상황을 반영하여 결정하였다.

발생된 7,000개의 레이더 데이터 중에서 무작위로 80 $\%$ 를 학습에 사용하고, 나머지 $20 \%$ 는 신호 분류 성능을 평가하기 위해 사용한다. 모의실험은 총 10 번 에폭(epoch) 의 평균치를 나타낸다. 각 에폭당 5 번 반복하여 레이다의 테스트 데이터를 바꿔가며 모두 사용한다.

그림 11 은 특징변수 값의 오차율에 따른 분류 성능을 나타낸다. RF 오차는 펄스폭이 좁아 반송파의 주파수를 정확하게 측정하기 어렵기 때문에 발생한다. 또 PRI의 경 우는 반사된 펄스의 모양이 완전한 사각파가 아니라, 양 옆으로 퍼지게 되어 발생한다. 그림을 보면 RF와 PRI값

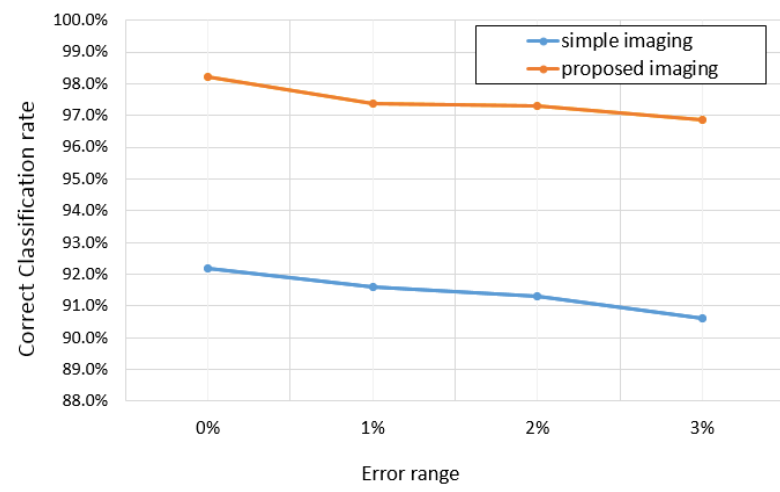

그림 11. PDW 데이터의 오차에 따른 분류기의 성능

Fig. 11. Performance of the classifier with the error ratio of the PDW data.

만 이용하여 단순하게 영상을 형성한 경우(단순 영상으 로 표시)보다 최대값 및 최소값을 반영한 영상(제안 영상 으로 표시)의 분류 성능이 약 $6 \%$ 정도 우수한 것을 볼 수 있다. 두 방식 모두 오차율이 증가함에 따라 분류 성능 은 약간씩 감소한다.

그림 12는 누락률에 따른 분류 성능을 나타낸다. 누락 은 실제 레이다 신호를 수집할 때 잡음이나 다른 신호의 간섭에 의해 펄스를 검출하지 못하는 경우가 발생한다. 그림에서 누락률이 증가함에 따라 분류 성능이 감소하는 모습을 볼 수 있다.

그림 11 과 그림 12 에서 오차율이 $0 \%$ 인 경우 또는 누 락률이 $0 \%$ 인 경우는 성능에 미치는 외부의 영향이 전혀

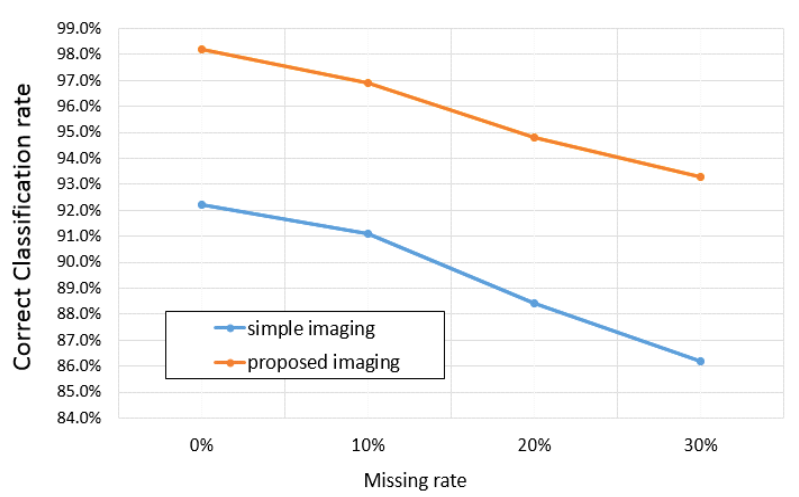

그림 12. PDW 데이터의 누락에 따른 분류기의 성능

Fig. 12. Performance of the classifier with the missing rate of the PDW data. 
없는 이상적인 경우에 해당한다. 따라서 이 경우의 두 방 식의 인식률의 차이는 개선 방식을 적용함으로써 얻어진 성능의 향상을 나타낸다.

모의실험을 통해 데이터를 생성하는 경우, 실제의 데 이터와 다른 상황이 발생한다. 즉, 실제로 데이터를 수집 할 때는 연속적인 누락이 거의 발생하지 않는다. 그러나 모의실험을 통해 데이터를 생성하는 경우에는 누락 펄스 를 확률적으로 결정하기 때문에 여러 개가 연속적으로 누락되는 경우가 발생한다. 특히 PRI는 펄스와 펄스 사이 간격을 뜻하는데, 연속적으로 누락된 경우 데이터 값이 급격하게 커진다. 따라서 데이터에 의해 누락률이 증가할 수록 분류 성능이 크게 감소하게 되는데, 그 원인은 주로 PRI 때문이다. 그림에서 보면 단순 영상 형성 방법이 좀 더 급하게 성능이 감소하는 것을 알 수 있다.

한편, 펄스의 누락이 발생하여 영상을 완성하기 위한 데이터 개수가 부족한 경우, 부족한 개수만큼 앞부분을 복사하여 순환적으로 채워 넣는다. 이 방법은 패턴의 불 연속이 단 한 번 발생하기 때문에 $\mathrm{CNN}$ 분류기에 미치는 영향은 크지 않을 것으로 판단된다.

\section{$\mathrm{V}$. 결 론}

이 논문에서는 기계학습 방법 중 $\mathrm{CNN}$ 을 적용하여 레 이다 신호를 분류하는 방법을 제시하였다. 펄스 레이다 신호를 특징짓는 특징변수로 RF와 PRI를 사용하여 $\mathrm{CNN}$ 입력을 위한 영상 데이터를 생성하였다.

모의실험을 통해 RF와 PRI의 특징변수 데이터만을 사 용하여 영상을 형성한 방식보다 특징변수 값과 더불어 특징변수의 최소값 및 최대값을 반영하여 영상을 형성한 경우 더 우수한 성능을 나타내는 것을 확인하였다. 두 경 우 모두 데이터의 오차와 누락이 증가함에 따라 분류 성 능이 저하하는 것을 볼 수 있었다. 특히 펄스의 누락은 분 류기의 성능에 크게 영향을 미친다. 이것은 연속적으로 펄스가 누락된 경우 PRI 값이 매우 커지기 때문이다. 실 제 상황을 고려하여 데이터를 생성하면 분류 성능은 약 간 향상될 것으로 판단된다.

한편, 모의실험 결과, 제안 방법은 라이브러리 기반 방 법에서는 그 정확성을 예측할 수 없는 학습 데이터에 포
함되지 않은 새로운 레이다의 데이터에 대해서도 최고 약 $98 \%$ 이상의 성능을 나타내는 것으로 나타났다. 따라 서 이것은 기존의 라이브러리 기반 분류 방법을 충분히 대체할 수 있을 것으로 판단된다.

\section{References}

[1] S. A. Vakin, R. H. Dunwell, and L. N. Shustov, Fundamentals of Electronic Warfare, Boston/London, Artech House, 2001.

[2] 장재원, 안태남, 이광일, "전자보호 및 사이버 방어와 함께 진화하는 전자전 기술의 발전방향," 전자파기술, 24(6), pp. 3-13, 2013년 11월.

[3] R. G. Wiley, ELINT: The Interception and Analysis of Radar Signals, Artech House, Boston/London, 2006.

[4] 한연희, "기계학습 기반 네트워크 지능화," 한국전자 파학회논문지, 28(5), pp. 17-22, 2017년 9월.

[5] Y. LeCun, Y. Bengio, and G. Hinton, "Deep learning," Nature, vol. 521, pp. 436-444, May 2015.

[6] S. H. Kong, M. Kim, L. M. Koang, and E. Kim, "Automatic LPI radar waveform recognition using CNN," IEEE Access, vol. 6, pp. 4207-4219, 2018.

[7] S. J. Hong, Y. G. Yi, J. Jo, and B. S. Seo, "Classification of radar signals with convolutional neural networks," in 2018 Tenth International Conference on Ubiquitous and Future Networks(ICUFN), Prague, Jul. 2018, pp. 894-896.

[8] I. S. Kim, S. Y. Hwang, "An effective online training algorithm by partitioning bounding box for visual object tracking using convolutional neural network," The Journal of Korean Institute of Communications and Information Sciences, vol. 42, no. 6, pp. 1117-1128, Jun. 2017.

[9] S. M. Yang, W. J. Song, I. S. Choi, and S. J Yoo, "Implementation of deep learning-based motion classification system for IoT device control in ultrasonic sound environments," The Journal of Korean Institute of Communications and Information Sciences, vol. 42, no. 9, pp. 1796-1805, Sep. 2017. 
홍 석 준 [충북대학교/석사과정]

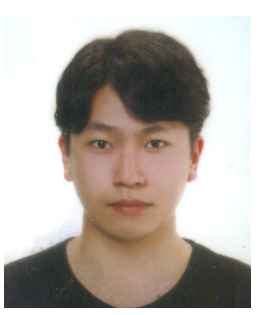

2017년 2월: 청주대학교 반도체공학과 (공 학사)

2017년 3월 현재: 충북대학교 전자공학 과 석사과정

[주 관심분야] 레이다 신호 처리
이 상 길 [동아방송예술대학교/교수]

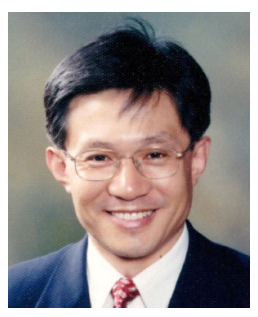

1981년 2월: 서울대학교 전자공학과 (공학 사)

1983년 2월: 서울대학교 전자공학과 (공학 석사)

1994년 2월: 서울대학교 전자공학과(공학 박사)

2014년 9월 현재: 동아방송예술대학교 방송예술융합학부 교수

[주 관심분야] 영상신호처리, 영상 압축, 가상현실

\section{서 보 석 [충북대학교/교수]}

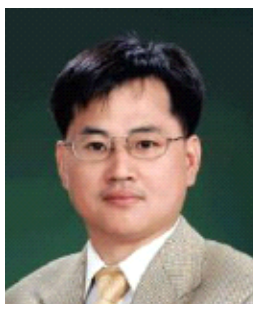

1987년 2월: 서울대학교 전자공학과 (공학 사)

1989년 2월: 서울대학교 전자공학과 (공학 석사)

1997년 2월: 서울대학교 전자공학과 (공학 박사)

2004년 9월 현재: 충북대학교 전자공학 과 교수

[주 관심분야] 통신신호처리, 적응신호처리, 레이다 신호처리

\section{조 제 일 [국방과학연구소/선임연구원]}

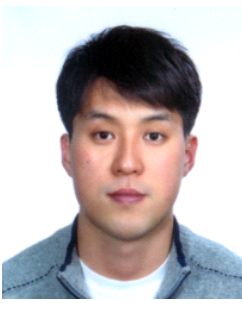

2000년 2월: 경북대학교 전기전자공학부 (공학사)

2005년 2월: 경북대학교 전자공학과 (공학 석사)

2005년 3월 현재: 국방과학연구소 선임 연구원

[주 관심분야] 레이다 신호처리 